\title{
Time-Motion AnAlysis of InTERnational AND National LeVel Futsal
}

\author{
Sera N. Dogramaci, Mark L. Watsford, and Aron J. Murphy \\ School of Leisure, Sport and Tourism, University of Technology, Sydney, Kuring-Gai Campus, Lindfield, New South Wales, \\ Australia
}

\begin{abstract}
Dogramaci, SN, Watsford, ML, and Murphy, AJ. Time-motion analysis of international and national level futsal. J Strength Cond Res 25(3): 646-651, 2011-Futsal is the Fédération de Internationale Football Association's officially recognized fivea-side indoor soccer, which although increasing in popularity worldwide, lacks the Australian or other English language research necessary to enable the growth of the sport. The purpose of this study was to establish a comprehensive overview of the demands of futsal by a time-motion analysis on 8 Australian National Team players and 10 State League Team players over 4 futsal matches. The study analyzed 6 locomotor activity categories, focusing on total distance covered, total duration of activities, total frequency of activities, effort distance, and effort duration. The national team covered a $42 \%$ greater overall distance than the state league team. In terms of relative data normalized for match duration, only the standing duration value was significantly different between the teams. Furthermore, futsal players of elite and subelite level in Australia perform a change in activity every 8-9 seconds on the court, and the national team athletes attained a higher, yet nonsignificant, average match-play velocity. This may be because of the national futsal athletes participating in an extended game duration, potentially suggesting that higher levels of competition facilitate a higher intensity of match play and greater physiological demands on individual players. Apart from the differences in timing structure and overall metabolic work, there was no real difference between the levels of competition within the Australian futsal analysis, although at higher levels of competition, there may be a need for more recovery because of the elevated intensity of the match. When comparing the data with other countries, however, Australian
\end{abstract}

Address correspondence to Sera N. Doğramacı, sera.dogramaci@uts. edu.au.

25(3)/646-651

Journal of Strength and Conditioning Research

(c) 2011 National Strength and Conditioning Association

Journal of Strength and Conditioning Research futsal players produce less distance and duration than Spanish futsal players.

KEY WoRDs indoor soccer, effort profile, team sport performance, intermittent exercise

\section{INTRODUCTION}

$\mathrm{F}$ utsal, the Fédération de Internationale Football Association's officially recognized five-a-side indoor soccer, is a physically demanding intermittent sport that, because of the unlimited substitutions permitted, has a high-intensity energy demand during match play and is fast moving from the spectator's perspective $(3,4,6,7,9)$. Futsal was introduced to Australia in 1972 and although the Australian men's national team has participated in all but one Futsal World Championship, futsal remains an amateur sport in Australia with 30,000 registered players (8). Because futsal is a developing sport in certain countries with more than 12 million players across 100 countries (9), a detailed understanding of the physical requirements would certainly aid in the improvement of performance. There are currently few studies reporting the match demands of futsal; however, those small number of studies have provided a greater understanding of the player loading and intensity requirements of athletes during match play $(2-4,7)$.

The identification of key performance aspects is important because it potentially affects various aspects of the game, namely, training methods. Time-motion analysis provides an objective assessment of player demands and enables researchers to calculate the distance covered by a subject in a given sport, the time spent, and the frequency of various match and movement actions and to determine movement patterns and work-rate profiles, the apparent onset of fatigue, and an estimate of the fitness of the subject $(3,4,11)$. This method of analysis has been used in a wide variety of sports including basketball (1), field hockey (14), rugby league (13), and soccer $(5,11)$; however, match characteristics and skill components are not accounted for in a time-motion analysis.

The purpose of this study was to establish a comprehensive overview of the demands of futsal by quantifying and comparing the activity patterns of subelite and elite level Australian futsal athletes during match play. A time-motion analysis of rugby league demonstrated that differences exist among 
physical performance characteristics of semielite and elite athletes (13). With no national futsal league currently being played in Australia, the New South Wales Premier League is the highest level of futsal competition, with several players participating in the competition also being members of the Australian National Team. Of the available research, no previous futsal study has conducted a time-motion study comparing different levels of competition. This study, therefore, has the potential to determine the differences between the 2 levels of competition in futsal, enabling training programs to be designed targeting specific areas of physical performance. It should be noted that this study assessed movement patterns of futsal athletes, and although there may have been differences between match skills such as passing success, these were not examined.

Because of the differences in timing of the matches, it was hypothesized that the Australian national (elite) players would cover a greater total distance, particularly in highintensity activities, and perform a greater number of movement activities than the State League (subelite) players during match play. However, when expressed as a percentage of overall duration, it was hypothesized that the elite players would spend a greater proportion of time in high-intensity activity than the subelite players.

\section{Methods}

\section{Experimental Approach to the Problem}

To assess the differences in match play between elite and subelite futsal players, a time-motion analysis was conducted during match play with a comparison of distance, duration, and frequency values. Actual raw values were converted into relative values and normalized for total match duration, to allow an accurate comparison, taking into account the differences in timing of the matches.

\section{Subjects}

A total of 18 male futsal athletes participated in this study, from a New South Wales State League Team $(n=10$; age, 15-19 years; height and weight unavailable) and from the Australian National Team $(n=8$; age, $25.5 \pm 3.8$ years; height, $1.76 \pm 0.07 \mathrm{~m}$; and weight, $74.8 \pm 4.7 \mathrm{~kg}$ ). These teams were selected for this study because they were a representative sample of subelite and elite Australian futsal players, thereby permitting a comparison between levels of performance in Australian futsal. Players were only studied if they played in both of the matches that were analyzed for each level and participated in a considerable part of each match (minimum match time of 10 minutes). No goalkeepers were included in the trial. Players were only studied if they played in both of the matches that were analyzed for each level and participated in a considerable part of each match (minimum match time of 10 minutes).

Informed consent from both teams was obtained before conducting the study. The University of Technology, Sydney, Human Research Ethics Committee approved the methodology and procedures used in this study.

\section{Procedures}

For each match assessed, match activities were monitored by means of video recording. Two digital video cameras (Panasonic, Osaka, Japan, and JVC, Yokohama, Japan) were set up, both equipped with a fish-eye lens, allowing for each camera to cover one-half of the futsal court. All matches were played at the same venue or a venue with the same court dimensions, thereby eliminating any potential differences that may arise from different court dimensions. The cameras were placed $10 \mathrm{~m}$ away from the sideline, approximately $2 \mathrm{~m}$ either side of the half-way line, and $10 \mathrm{~m}$ from ground level on the sideline of the court. Both cameras were set up on tripods 1.5 $\mathrm{m}$ high and angled inward, consequentially providing a camera height of $11.5 \mathrm{~m}$ above the playing surface.

All players were tracked in both matches, for the duration of each match consisting of two 20-minute halves. It should be noted that the timekeeping for the international matches only included times when the ball was in play, therefore the matches were approximately 80 minutes in duration, whereas the State League timekeeping began at kickoff and ran for 40 minutes, with only halftime and time-out breaks excluded from the clock time.

The video footage from the matches was transferred onto videotape to enable postmatch analysis. Because 2 cameras recorded the matches, 2 television sets were required. The television sets were placed side by side, and the matches were played and timed to allow the game to be viewed as it was played. A computer program called "Event Recorder" (KB Technologies, Sydney, Australia) was used in this study. The identification of the speed of each movement activity was determined by the subjective view of one trained and experienced observer, after having established the reliability and validity of the use of the Event Recorder for notational analysis. This was achieved by comparing values derived from the Event Recorder with known distances on a marked out course, replicating 10 minutes of futsal movement patterns (unpublished data). Notational analysis of movement activities for the participants was carried out considering the following categories: standing $\left(0 \mathrm{~m} \cdot \mathrm{s}^{-1}\right)$, walking $\left(1 \mathrm{~m} \cdot \mathrm{s}^{-1}\right)$, jogging $\left(3 \mathrm{~m} \cdot \mathrm{s}^{-1}\right)$, running $\left(5 \mathrm{~m} \cdot \mathrm{s}^{-1}\right)$, sprinting $\left(7 \mathrm{~m} \cdot \mathrm{s}^{-1}\right)$, and sideway or backward movement $\left(3 \mathrm{~m} \cdot \mathrm{s}^{-1}\right)$, which included jockeying an opposing player. The movement activities were later divided into either low-intensity activity (those under $5 \mathrm{~m} \cdot \mathrm{s}^{-1}$ such as standing, walking, jogging, and sideway or backward movement) or high-intensity activity (those over $5 \mathrm{~m} \cdot \mathrm{s}^{-1}$ such as running and sprinting). The movement velocities used to delineate between movement activities were also based on the velocities selected from the methodologies of several researchers in other team sports $(3,4,7,11,14)$.

The use of one researcher conducting the analysis eliminated any interindividual variation in the measures. Each movement activity was timed to 0.1 seconds, and the total duration for each activity was calculated. Such an analysis further permitted the calculation of the frequency of the number of times each movement activity was performed 
by each individual player. Furthermore, the total distance covered in each movement activity was calculated using the total duration of each activity by the speed assigned to it. In addition, by dividing the total duration or distance of a movement activity by its frequency, the average effort duration and distance of each individual activity performed, respectively, were calculated. The activity profiles of the players were then defined as functions of the first and second halves of the game. These variables provide an idea on the physiological demands of the game, including changes in in-

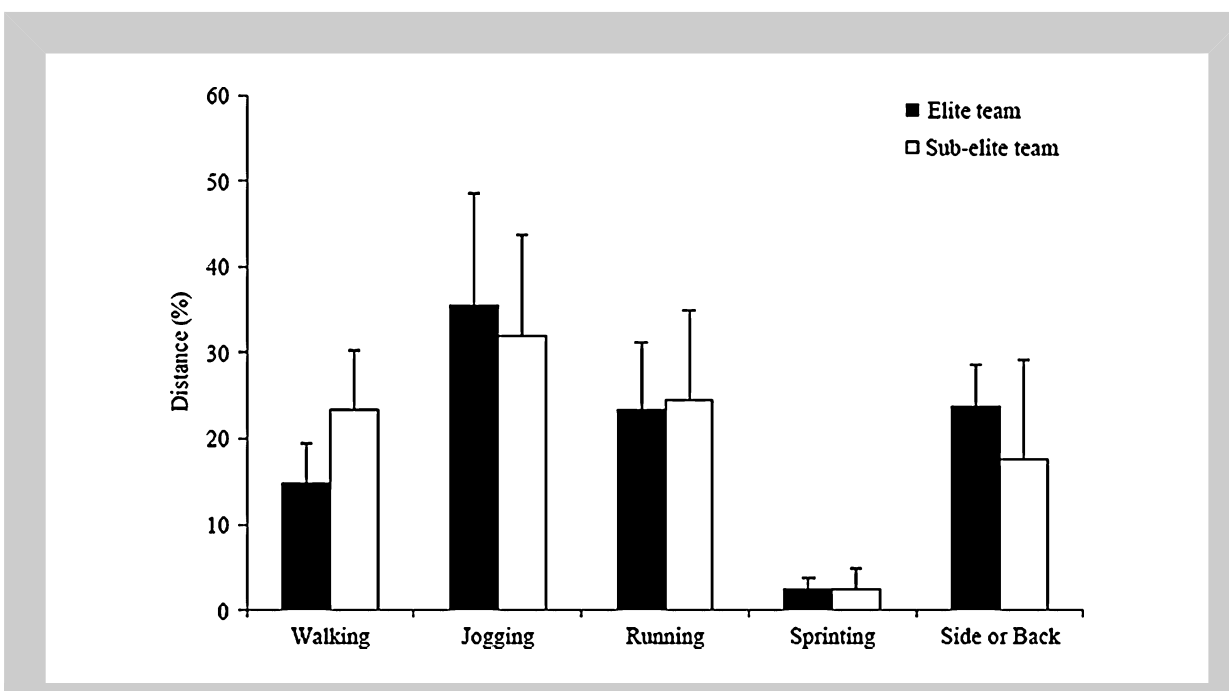

Figure 1. Relative distance values for the elite and subelite teams. tensity and work rate. This information can be used to alter training programs as necessary, thereby improving match performance.

\section{Statistical Analyses}

The Event Recorder program used to track movement patterns was deemed to be reliable, with a technical error of measurement of $2.7 \%$ for distance and $3.3 \%$ for duration (unpublished data). After the data reduction of the match analysis, independent samples $t$-tests were performed using SPSS version 16.0 between the data obtained from the elite team and the subelite team. These tests were designed to assess differences in overall performance on the dependent variables including total distance covered, total duration, total frequency, average effort distance, and average effort duration of movement activities. Significance was set at $p \leq$ 0.05 , with descriptive statistics for all variables reported as mean $\pm S D$.

\section{Results}

Because of the differences in the timekeeping of the matches, whereby the total length of the international matches was approximately 80 minutes and the State League matches were 40 minutes, the data were analyzed as absolute scores (raw data) and relative scores (relative to total distance, time, and frequency) to enable delineation between the 2 teams.

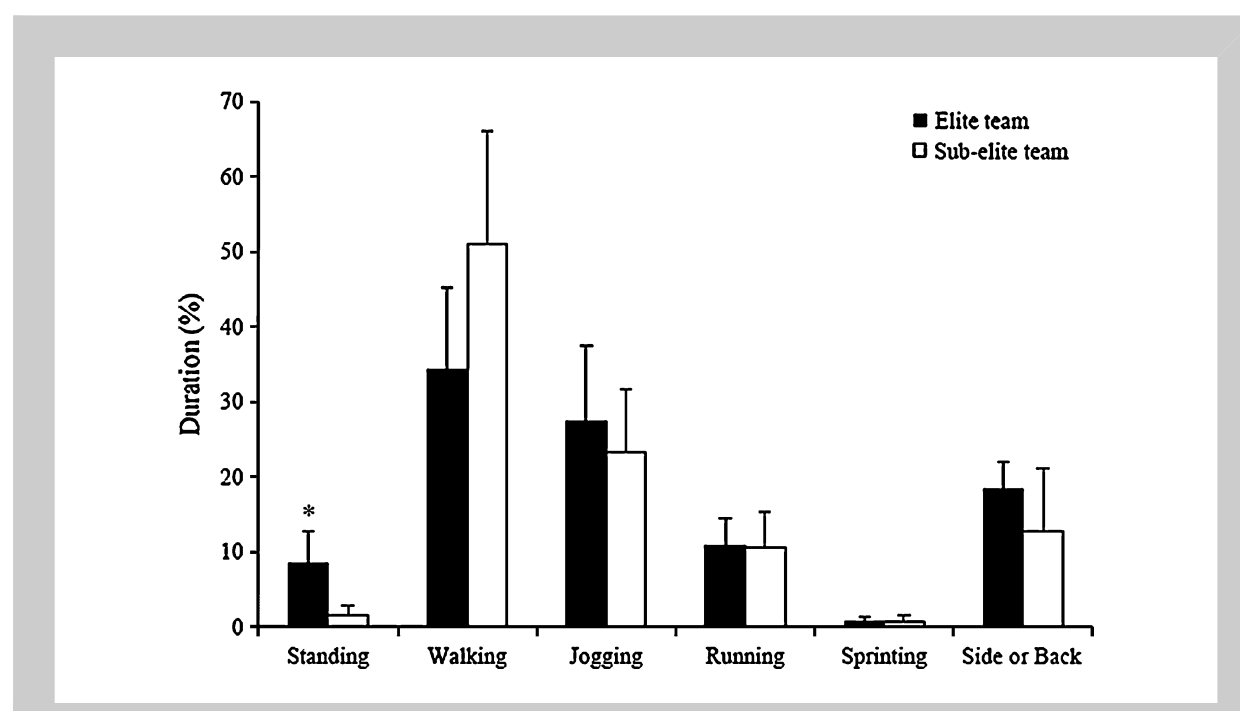

Figure 2. Relative duration values for the elite and subelite teams. *Significantly different from the State League team $(p<0.05)$. 
TABLE. Mean $\pm S D$ of locomotor activities for both teams.

\begin{tabular}{|c|c|c|c|c|c|c|c|}
\hline & Stand & Walk & Jog & Run & Sprint & Side or Back & Total \\
\hline \multicolumn{8}{|l|}{ Australia } \\
\hline Distance (m) & $0.0 \pm 0.0$ & $635 \pm 204$ & $1,521 \pm 558^{*}$ & $999 \pm 333$ & $106 \pm 56$ & $1,016 \pm 209^{*}$ & $4,277 \pm 1,030$ * \\
\hline Duration (s) & $156 \pm 79^{\star}$ & $635 \pm 204$ & $507 \pm 186^{*}$ & $200 \pm 67$ & $15 \pm 8.6$ & $339 \pm 70^{*}$ & $1,852 \pm 466^{*}$ \\
\hline Frequency $(n)$ & $19 \pm 7.7^{*}$ & $121 \pm 29$ & $142 \pm 27^{\star}$ & $74 \pm 22^{\star}$ & $7.4 \pm 3.3$ & $105 \pm 19^{\star}$ & $468 \pm 77$ \\
\hline Effort distance $(m)$ & $0.0 \pm 0.0$ & $5.1 \pm 0.6^{*}$ & $11 \pm 2.8$ & $14 \pm 1.1$ & $13 \pm 3.4$ & $9.6 \pm 0.7$ & \\
\hline Effort duration (s) & $7.8 \pm 4.4^{\star}$ & $5.1 \pm 0.6^{*}$ & $3.5 \pm 0.9$ & $2.8 \pm 0.2$ & $1.9 \pm 1.0$ & $3.2 \pm 1.6$ & \\
\hline \multicolumn{8}{|l|}{ State league } \\
\hline Distance (m) & $0.0 \pm 0.0$ & $706 \pm 210$ & $965 \pm 351$ & $737 \pm 313$ & $76 \pm 69$ & $527 \pm 349$ & $3,011 \pm 999$ \\
\hline Duration (s) & $23 \pm 18$ & $706 \pm 210$ & $322 \pm 117$ & $148 \pm 63$ & $11 \pm 9.8$ & $176 \pm 116$ & $1,384 \pm 411$ \\
\hline Frequency (n) & $8.9 \pm 6.7$ & $98 \pm 28$ & $96 \pm 21$ & $47 \pm 23$ & $5.3 \pm 4.1$ & $51 \pm 18$ & $306 \pm 81$ \\
\hline Effort distance $(m)$ & $0.0 \pm 0.0$ & $6.5 \pm 1.0$ & $9.1 \pm 2.5$ & $15 \pm 1.1$ & $7.8 \pm 6.6$ & $11 \pm 9.7$ & \\
\hline Effort duration (s) & $2.2 \pm 1.2$ & $6.5 \pm 1.0$ & $2.9 \pm 0.6$ & $3.0 \pm 0.2$ & $1.6 \pm 1.0$ & $2.9 \pm 1.6$ & \\
\hline
\end{tabular}

*Significantly different from the State League team $(p<0.05)$.

between the teams for any of the relative distance variables, as can be observed in Figure 1.

A significant difference was evident between the teams for overall playing time $(p=0.04)$, with the average player playing $1,852 \pm 466$ seconds $(30.4 \pm 7.77$ minutes $)$ for the international match and 1,384 \pm 411 seconds $(23.1 \pm 6.85$ minutes) for the State League match. When considering total match duration, the average elite player was on the court for $38 \%$ of the game, whereas the average subelite player was active for $58 \%$ of the game. Furthermore, the elite team exhibited a $593 \%$ greater overall raw standing duration $(p=0.04)$ and relative standing duration $(p<$ $0.05)$ than the subelite team. The elite team also produced a $54 \%$ greater raw jogging duration $(p=0.03)$ and a $93 \%$ greater raw sideway or backward duration $(p<0.01)$. The raw values for both teams are presented in the Table, with relative values presented in Figure 2.

A total of $468 \pm 77$ movement activities were performed by the elite team, with $249 \pm 54$ performed in the first half and $219 \pm 40$ in the second half. The subelite team performed a total of $306 \pm 81$ movement activities throughout the game, with $148 \pm 44$ of these performed in the first half and $158 \pm 57$ in the second half. This equated to a $12 \%$ decrease in movement activity transitions in the second half for the elite team and a $7 \%$ increase for the subelite team. Furthermore, it was observed that the elite team performed a change in activity every 9 seconds, or 6.7 different activities each minute, and the subelite performed a change in activity every 8 seconds, or 7.7 different activities per minute. Several significant differences were observed within the raw frequency variables, where the elite team performed a greater number of standing, jogging, running, and sideways or backward activities than the subelite team, which can be seen in the Table. The relative frequency values for both teams can be seen in Figure 3, although no significant differences were detected.

A summary of the average movement effort distances and durations can be found in the Table. It was observed that the elite team covered 22\% less distance and spent 22\% less

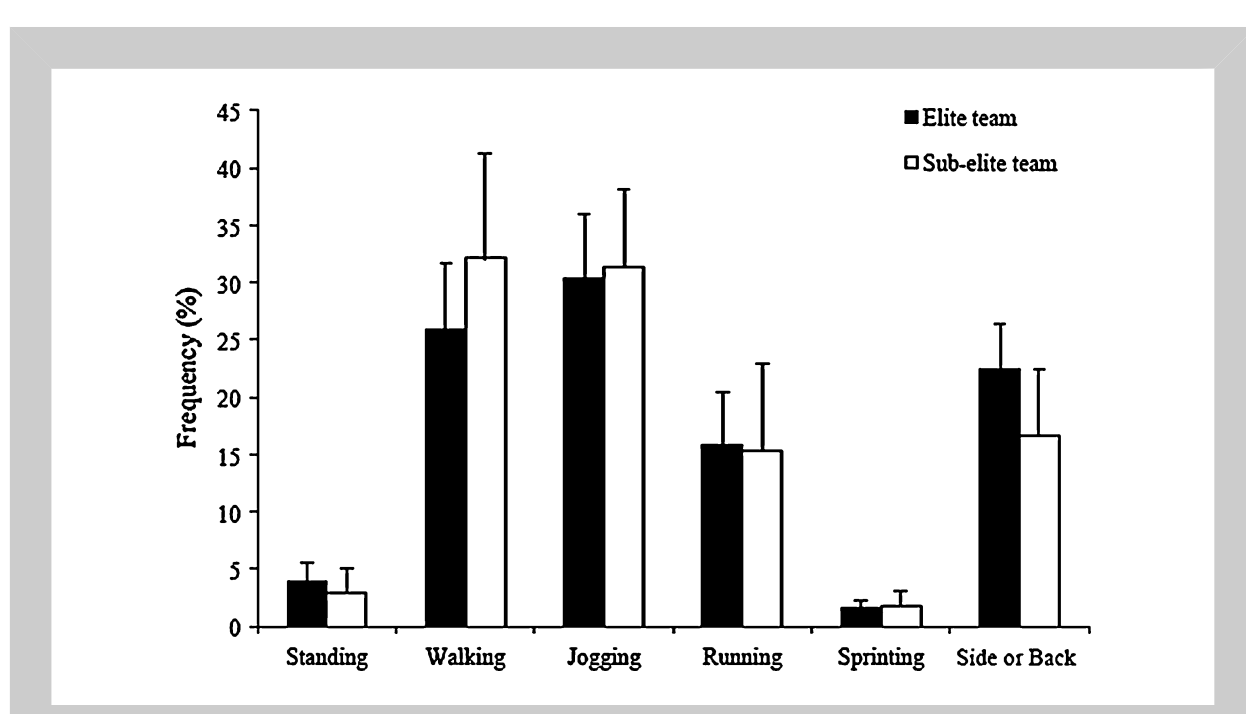

Figure 3. Relative frequency values for the elite and subelite. 
duration for each average walking effort than the subelite team $(p<0.01$ and $p<0.01$, respectively). Furthermore, the elite team revealed a $256 \%$ greater standing effort duration $(p=0.01)$ compared with the subelite team.

\section{Discussion}

This study is the first to conduct a time-motion analysis comparing 2 levels of futsal competition. The significant differences evident in the present study were most likely caused by the differences in the duration of the game, where the international matches totaled approximately 80 minutes and the State League matches totaled 40 minutes. For this reason, relative data were analyzed and reported to enable an accurate comparison of results between the teams. Interestingly, there were no significant differences between the teams for any of the relative data, with the exception of standing duration where the elite team exhibited a greater value than the subelite team. There was a tendency for more walking by the subelite team than the elite team, and there was a trend for the elite team to perform a greater distance, duration, and frequency of sideway or backward movement than the subelite team. This may be a choice of tactics by elite athletes, whereby jockeying or tracking a player is more efficient than high-intensity runs. It is also possible that, without taking other factors into account such as ball-specific skills and the influence of the opposition, Australian futsal players perform similar movement patterns at the subelite and elite levels, hence the absence of any differences between the relative data.

Previous studies investigating the movement patterns of futsal have been proved valid and reliable $(3,4,7)$. Although there are slight differences in the methodologies used, the similarities warrant a fair comparison between these studies and the present study. In congruence with the hypothesis, the present study demonstrated that the elite team covered a significantly greater total distance than the subelite team. The total distance covered for both teams remained in accordance with previous futsal studies ranging between 2,575 and $4,313 \mathrm{~m}(3,4)$. Both teams experienced a nonsignificant decrease in total distance covered in the second half compared with that in the first, whereas previous futsal studies have demonstrated an increase in the distance covered (3), which may have been because of a longer second-half duration than the first, with players walking during breaks in play. The elite players may have been standing during breaks in play, and because the State League matches did not include breaks in play in the total match time, the decrease in distance may be attributed to fatigue. In a comparable study, the physical demands between a semielite and an elite rugby league teams were found to be similar, with higher physical demands placed on the elite players during the first half of the match, potentially causing a reduction in physical performance in the second half (13). It was hypothesized that the elite players would spend a greater proportion of time engaged in high-intensity activity than the subelite players. This hypothesis is not supported because there were no significant differences in either the raw or the relative data for running or sprinting. Furthermore, the elite and subelite futsal players covered a reduced sprinting distance, both in raw and in relative values, compared with professional Spanish futsal athletes (76-106 vs. $349 \mathrm{~m} ; 2.5-8.9 \%$ ) (3). Despite the potential methodological differences between studies, this may have implications for performance of Australian futsal players at the international level.

The elite players tended to increase the low-intensity activity distance covered in the second half of match play and decrease the high-intensity activity distance covered, which is similar to previous futsal studies (3). This may have been because of the tactics involved at different levels of play or because the elite players have more experience in the game compared with the subelite players, perhaps conserving energy, particularly toward the end of the match. Naturally, match outcome is a primary determinant of the intensity exhibited during futsal match play. A close match undoubtedly results in a higher relative intensity toward the end of a match, with a large points margin potentially leading to a reduction in intensity. Within the limitations of the current study, intensity output was not examined with reference to progressive match status; however, this is one area for future research, similar to the analysis conducted by Rampinini et al. (12).

Average court velocity of 139.8 and $130.1 \mathrm{~m} \cdot \mathrm{min}^{-1}$ was calculated for the elite and subelite teams, respectively, and this result was not significantly different. Professional Spanish futsal athletes achieve an average court velocity of 117-121 $\mathrm{m} \cdot \mathrm{min}^{-1}(3,7)$, which may suggest that Australian athletes play at a greater intensity, despite the apparent differences in the distance covered by sprinting. Within the limitations of the current study, Australian male futsal athletes seem to cover a greater distance during match play than their Spanish counterparts. Furthermore, Australian players sprint for less than $1 \%$ of the total match time, which is less than that seen in professional Spanish futsal of 5\% (7). Potentially, Spanish futsal athletes rely on skill rather than on distance covered or adopt an alternate technical and tactical approach for superior performance. This could be influenced by methodological differences or individual coaching style, which inherently determines these types of results. Unfortunately, such a comparison is beyond the scope of this article.

The present study also demonstrated that the elite players performed a greater number of movement activities than the subelite players. This result was in congruence with the hypothesis and was anticipated because of the greater time on the court. Furthermore, the elite team covered an average distance of $13 \mathrm{~m}$ per sprinting effort over 1.9 seconds, which is similar to that seen in professional Spanish futsal of $10.5 \mathrm{~m}$ over 1.95 seconds (7). Additionally, it was revealed that futsal athletes in Australia perform a change in activity every 8-9 seconds. The frequency of each movement activity in relation 
to number of times performed per minute and occurrence of each activity have been previously reported for futsal, demonstrating that low-intensity activities are performed 4.31 times per minute of match play, 1.64 times for mediumintensity activities, 1.46 times for high-intensity activities, and 1.17 times for maximum-intensity activities (4). This equates to a change in activity every 7 seconds, suggesting that Australian futsal athletes engage in fewer changes of movement activities than their Spanish counterparts. Such results may be because of the Spanish athletes' greater experience and participation in a higher intensity of match play. Alternatively, this may also be because of the differences in methodologies across time-motion analysis research. This is an area for further investigation using standardized intensity categories between different nationalities.

In relation to the average effort distances and durations, the elite team spent a significantly greater average duration for each standing effort than the subelite team and averaged a lower distance and duration for each walking effort. Once again, this was because of the differences in the timing methods between levels of play. However, both teams covered less average walking effort distance and duration than that reported in previous futsal studies (4). Furthermore, the elite team tended to cover a greater distance and duration with each sprinting effort than the subelite team, and although this was not significant, it was concurrent with the hypothesis that the elite team would spend a greater distance and duration in high-intensity activities than the subelite team. It can be suggested that in futsal, low-intensity activity encompasses most of the match-play duration because of the need for recovery from high-intensity activity $(2,4,7)$. These results also support previous reports that higher levels of competition result in higher match-play intensity (12).

Based on the apparent reliance on recovery during futsal, it is essential that the development of a superior aerobic capacity is a priority in training (15). This may assist in delaying the onset of fatigue in the second half of match play, allowing athletes to maintain a high-performance intensity throughout the duration of the game, in addition to performing a greater frequency of movement activities. Such an allowance may permit enhanced recovery between work periods (14). A superior aerobic capacity may also result in an enhanced potential to cover a longer distance at a higher intensity during match play and a greater involvement in the game (10). Furthermore, because high-intensity activity and repeat sprint ability are major determinants for successful performance in team sports, including futsal, this should also be made a priority in training $(14,16)$. These training principles become even more important for subelite players making the transition to elite futsal. Although no significant differences were detected between the teams for relative data, the longer match duration in international games results in a greater distance covered and greater physiological demands on individual players.

\section{Practical Applications}

During futsal match play, most of the distance covered by Australian players consists of low-intensity movement activities. Elite players cover a greater overall distance than the subelite players because of attaining a higher average match-play velocity and the extended game duration. Futsal athletes tend to decrease the overall distance covered in the second half of a match compared with that in the first half because of the onset of fatigue from this high-intensity intermittent sport. At higher levels of competition, there may be a need for more recovery because of the elevated intensity of the match.

\section{REFERENCES}

1. Abdelkrim, NB, El Fazaa, S, and El Ati, J. Time-motion analysis and physiological data of elite under-19-year-old basketball players during competition. BrJ Sports Med 41: 69-75, 2007.

2. Barbero Álvarez, JC, and Castagna, C. Activity patterns in professional futsal players using global position tracking system. J Sports Sci Med 6: 208-209, 2007.

3. Barbero-Álvarez, JC, Soto, VM, Barbero-Álvarez, V, and Granda-Vera, J. Match analysis and heart rate of futsal players during competition. J Sports Sci 26: 63-73, 2008.

4. Barbero-Álvarez, JC, Soto, V, and Granda, J. Effort profiling during indoor soccer competition. J Sports Sci 22: 500-501, 2004.

5. Burgess, DJ, Naughton, G, and Norton, KI. Profile of movement demands of national football players in Australia. J Sci Med Sport 9: 334-341, 2006

6. Burns, T. Holistic Futsal: A Total Mind-Body-Spirit Approach. New York, NY: Lulu Press, 2003.

7. Castagna, C, D' Ottavio, S, Vera, JG, and Alvarez, JC. Match demands of professional futsal: A case study. J Sci Med Sport 12: 490-494, 2009.

8. Football Federation Australia. What is futsal. Available at: http:// www.footballaustralia.com.au/Comunity/default.aspx?s $=\mathrm{comm}_{-}$ futsal_about. Accessed February 19, 2006.

9. Gorostiaga, EM, Llodio, I, Granados, C, Navarro, I, Ruesta, M, Bonnabau, H, and Izquierdo, M. Differences in physical fitness among indoor and outdoor elite male soccer players. Eur J Appl Physiol 106: 483-491, 2009.

10. Helgerud, J, Engen, LC, Wisløff, U, and Hoff, J. Aerobic endurance training improves soccer performance. Med Sci Sports Exerc 33: 1925-1931, 2001.

11. Mohr, M, Krustrup, P, and Bangsbo, J. Match performance of highstandard soccer players with special reference to development of fatigue. J Sports Sci 21: 519-528, 2003.

12. Rampinini, E, Coutts, AJ, Castagna, C, Sassi, R, and Impellizzeri, FM. Variation in top level soccer match performance. Int J Sports Med 28: 1018-1024, 2007.

13. Sirotic, AC, Coutts, AJ, Knowles, $\mathrm{H}$, and Catterick, C. A comparison of match demands between elite and semi-elite rugby league competition. J Sports Sci 27: 203-211, 2009.

14. Spencer, M, Lawrence, S, Rechichi, C, Bishop, D, Dawson, B, and Goodman, C. Time-motion analysis of elite field hockey, with special reference to repeated-sprint ability. J Sports Sci 22: 843-850, 2004.

15. Tomlin, DL and Wenger, HA. The relationship between aerobic fitness and recovery from high intensity intermittent exercise. Sports Med 31: 1-11, 2001.

16. Young, WB, McDowell, MH, and Scarlett, BJ. Specificity of sprint and agility training methods. J Strength Cond Res 15: 315-319, 2001. 